WEITE LU, Ph.D.

E-mail:weitelu@zstu.edu.cn

School of Civil and Architectural Engineering

Zhejiang Sci-Tech University

No. 928, Second Avenue, Xiasha Higher Education Zone,

Hangzhou, 310018, China
Intelligent Transport Systems (ITS)

Original Scientific Paper

Submitted: 3 June 2020

Accepted: 4 Dec. 2020

DOI: $10.7307 /$ ptt.v33i4.3617

\title{
EVALUATING SATISFACTION IN SHARED LANES AS PART OF SUSTAINABLE TRANSPORT INFRASTRUCTURE BY USING VR TECHNOLOGY - EVIDENCE FROM URBAN CHINA
}

\begin{abstract}
The concept of sharing transport infrastructure has become increasingly prominent in the sustainable society due to limited resources in urban cities. Shared lanes where cars, electric motorcycles, and bicycles are permitted have been promoted in urban China to overcome the shortage of road space available to meet the increasing traffic demand. Based on VR video and questionnaire survey, this study has identified that the levels of satisfaction of drivers, e-motorcyclists, and cyclists are associated with the factors of traffic condition and lane characteristics among various shared lanes. Based on the analysis of data by a multinomial ordered logistic regression model, the major findings of this study are summarised as follows: (1) Satisfaction was mainly affected by lane width, lane number, lane type, and presence of parking space in the driver group. (2) Lane width, lane number, lane type, presence of parking space, speed, and lateral separation were the main factors in the e-motorcyclist group. (3) For the group of cyclists, lane width, lane number, presence of slope, presence of parking space, speed, and lateral separation were identified as the main factors. Our study will help local government officials to design more effective sustainable transport infrastructures.
\end{abstract}

\section{KEYWORDS}

sustainable transport infrastructure; user satisfaction; traffic condition; lane characteristics; multinomial ordered logistic regression model.

\section{INTRODUCTION}

The transport infrastructure is the foundation of urban cities [1,2]. The level of transport infrastructure affects the travel of residents and the development of urban economic growth $[3,4]$. In a sustainable society, sharing the transport infrastructure has become very significant due to limited resources in urban cities [5].

As an extension to the concept of the shared lane, urban areas in China have introduced sharing among three modes of transport as a new solution. Although bicycle lanes segregated from other traffic are preferred from a bicycle safety point of view, bicycle and pedestrian shared lanes are adopted in a number of countries to economise on road space allocation $[6,7]$. The new approach taken by planners in China attempts to accommodate for the growth of electric motorcycles by introducing shared lanes for three modes: cars, electric motorcycles, and bicycles [8].

The term 'electric motorcycles' (or 'electric bicycles' in some literature) is applied here for battery-powered personal vehicles that have the appearance of conventional motorcycles. These electric motorcycles are installed with headlights, turn signals and horns, and with a $48-\mathrm{V}$ battery under the footboard [9]. Electric motorcycles have replaced conventional motorcycles in urban areas in China because conventional motorcycles in many big cities were banned by the local government in 2007 to reduce carbon emissions and address traffic safety problems attributed to the potential excessive speed of gasoline motorcycles.

The car/e-motorcycle/bicycle shared lanes were typically transformed from former 5-9 m-wide bicycle-only lanes in 2005 without an attempt to standardise the size of new shared lanes in urban China. These new shared lanes permit regular cars, battery powered motorcycles, and bicycles to share the lane. Trucks and similar large vehicles are prohibited. There are two different speed limits for traffic in the 
shared lane. Speed limit for bicycles and electric motorcycles is $15-20 \mathrm{~km} / \mathrm{h}$. Speed limit for cars is 30 $40 \mathrm{~km} / \mathrm{h}$. When space permitted, the right hand edge (China uses right-hand traffic) of the shared lane was converted to roadside parallel parking spaces for cars to alleviate the shortage of parking spaces in the city.

Local government officials claimed that shared lanes would increase the efficiency of road space and help to accommodate the increased number of motorised traffic. However, there are many studies which have pointed out the potential danger in the bicycle/ pedestrian shared lanes $[10,11]$ or motor vehicle/bicycle shared lanes $[12,13]$. However, there is scant literature about car/e-motorcycle/bicycle shared lanes to be found in other countries, and only a few studies presented in China. For example, National Bureau of Statistics of the People's Republic of China [14] recorded 1,522 accidents involving cyclists and 8,522 accidents involving electric motorcycles in these shared lanes for three modes in China in the year 2017. Li et al. [15] analysed 493 cases of collision events in the shared lanes in Changsha city and found that $64 \%$ of collision events involved electric motorcycles. Based on this literature, we have speculated there is a lack of safety for users of shared lanes and low user satisfaction compared to segregation of transport modes in dedicated lanes, particularly because of the sheer number of electric motorcycles allowed to use the shared lane.

Not only can user satisfaction measure the quality of the current infrastructure, it can also provide new ways of identifying influencing factors which may affect use. Therefore, evaluating the satisfaction of the three groups of shared lane users is a first important step in understanding and improving shared lanes in the sustainable society in China. Nevertheless, the local government does not have an approach to estimate the satisfaction of users. Previous literature shows that field survey and video survey are often used to evaluate the satisfaction in the field of transportation. The field survey obtains real perceptions of comfort by car drivers and cyclists. For instance, Landis et al. [16] placed one hundred and fifty participants (most were cyclists) in a shared lane to obtain their feedback. Bai et al. [17] used the same method to ask the perceptions of participants who used shared lanes. However, it is very difficult and dangerous for many participants to attend a field survey [18]. In order to protect the safety of participants, video survey is widely used to analyse the satisfaction of participants. For example, after taking video record- ings, two hundred participants were asked about the perceptions of satisfaction of a cycle-lane in a survey by Harkey et al. [19]. Lehtonen et al. [20] also invited participants to watch video clips and report the level of satisfaction about lanes. Lamb et al. [21] used the same method of showing video clips to participants to score the perceptions of danger in public roads for cyclists and police officers. The video survey has proven to be a useful method by previous studies; nevertheless, some researchers have pointed out that ordinary video recordings cannot provide an immersive environment to simulate lanes in the real world [22]. Therefore, neither method can obtain real perceptions of users towards shared lanes.

Nowadays, virtual reality (VR) technology is widely used in many research fields and provides an opportunity to evaluate the satisfaction of shared lane users by creating a safe and immersive environment to overcome the weakness of field and video surveys. Therefore, the main objective of this paper is to estimate the influencing factors that affect levels of satisfaction of users on different shared lanes in an urban city of China by using VR technology. This research project has set out to investigate user perceptions about such shared lanes in a questionnaire survey. Participants will be shown various shared lanes in a VR video and then will be asked to elaborate on how satisfactory these lanes present themselves. The association between the satisfaction of users, traffic condition, and lane characteristics will be examined based on a multinomial ordered logistic regression model. These studies will help local government officials to design more effective shared lanes and provide a methodology and analysed data to other countries which are also considering improving mixed traffic lanes.

The paper is structured as follows: Section 2 presents the data collection and the details of the research methodology. Section 3 continues with the model analysis and highlights the results of the survey. Section 4 discusses the results and limitations of this study. The final section outlines the conclusions of this research. In addition, some suggestions for further research are provided as well.

\section{MATERIALS AND METHODS}

\subsection{Data sources}

Hangzhou was selected for this study, which is the capital city of the Zhejiang Province located in the eastern region of China, with 16,596 square 
kilometres and 9.4 million people [23]. We made a list of twenty shared lanes to ensure that the selected shared lanes would represent a variety of characteristics (see Table 1). Figure 1 shows some typical shared lanes in the city. Traffic conditions (e.g. traffic volumes and speed of each transport mode) were captured by cameras. These video recordings will also be used in the questionnaire survey for the perception of satisfaction.

Participants in the questionnaire survey were randomly recruited from four communities located in different regions of the city. Participants were firstly asked about the main mode of transport used for commuting during the past year. The participants who used one of the three categories: car, e-motorcycle, or bicycle, were allowed to take the questionnaire survey. Participants using other transportation, such as subway etc. were excluded. Finally, two hundred and forty people (male: 135; female: 105) completed this study. As for the transport mode, there were 82 car drivers, 80 e-motorcyclists and 78 cyclists. The age range of

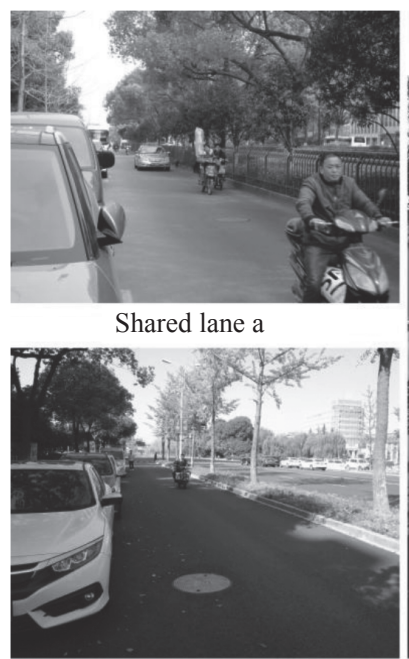

Shared lane b

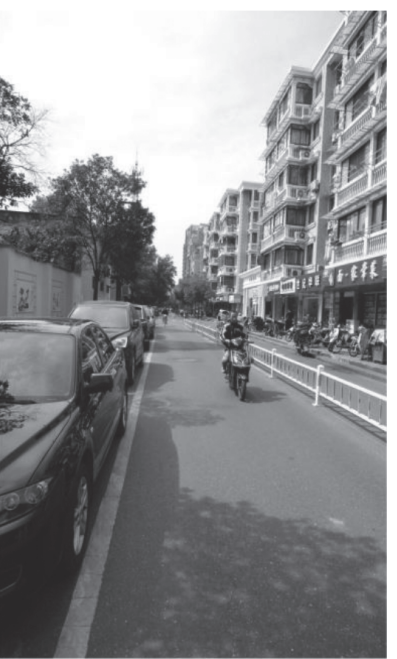

Shared lane c

Figure 1 - Shared lanes in different areas of Hangzhou City

participants was from teens to sixties. In addition, all participants self-reported their health condition to be good.

Table 1 - List of characteristics of shared lanes

\begin{tabular}{|c|c|c|c|c|c|c|c|c|c|c|}
\hline \multirow{2}{*}{ Lane } & \multicolumn{2}{|c|}{ Lane width $[\mathrm{m}]$} & \multicolumn{2}{|c|}{ Paved shoulder width [m] } & \multicolumn{2}{|c|}{ Speed limit for cars $[\mathrm{km} / \mathrm{h}]$} & \multicolumn{2}{|c|}{ Number of lanes } & \multicolumn{2}{|c|}{ Parking spaces } \\
\hline & $<7$ & $\geq 7$ & $<0.5$ & $\geq 0.5$ & $<40$ & $\geq 40$ & 1 & $\geq 2$ & Yes & No \\
\hline 1 & $\sqrt{ }$ & & - & - & $\sqrt{ }$ & & $\sqrt{ }$ & & & $\sqrt{ }$ \\
\hline 2 & $\sqrt{ }$ & & - & - & & $\sqrt{ }$ & $\sqrt{ }$ & & & $\sqrt{ }$ \\
\hline 3 & & $\sqrt{ }$ & - & - & $\sqrt{ }$ & & $\sqrt{ }$ & & $\sqrt{ }$ & \\
\hline 4 & & $\sqrt{ }$ & - & - & $\sqrt{ }$ & & & $\sqrt{ }$ & $\sqrt{ }$ & \\
\hline 5 & & $\sqrt{ }$ & - & - & $\sqrt{ }$ & & & $\sqrt{ }$ & $\sqrt{ }$ & \\
\hline 6 & & $\sqrt{ }$ & - & - & & $\sqrt{ }$ & & $\sqrt{ }$ & & $\sqrt{ }$ \\
\hline 7 & & $\sqrt{ }$ & - & - & & $\sqrt{ }$ & & $\sqrt{ }$ & & $\sqrt{ }$ \\
\hline 8 & & $\sqrt{ }$ & - & - & & $\sqrt{ }$ & $\sqrt{ }$ & & & $\sqrt{ }$ \\
\hline 9 & $\sqrt{ }$ & & - & - & $\sqrt{ }$ & & $\sqrt{ }$ & & & $\sqrt{ }$ \\
\hline 10 & $\sqrt{ }$ & & - & - & $\sqrt{ }$ & & $\sqrt{ }$ & & $\sqrt{ }$ & \\
\hline 11 & $\sqrt{ }$ & & - & - & & $\sqrt{ }$ & $\sqrt{ }$ & & $\sqrt{ }$ & \\
\hline 12 & $\sqrt{ }$ & & - & - & & $\sqrt{ }$ & $\sqrt{ }$ & & $\sqrt{ }$ & \\
\hline 13 & & $\sqrt{ }$ & $\sqrt{ }$ & & $\sqrt{ }$ & & & $\sqrt{ }$ & $\sqrt{ }$ & \\
\hline 14 & & $\sqrt{ }$ & $\sqrt{ }$ & & & $\sqrt{ }$ & $\sqrt{ }$ & & $\sqrt{ }$ & \\
\hline 15 & $\sqrt{ }$ & & $\sqrt{ }$ & & $\sqrt{ }$ & & $\sqrt{ }$ & & & $\sqrt{ }$ \\
\hline 16 & $\sqrt{ }$ & & $\sqrt{ }$ & & & $\sqrt{ }$ & $\sqrt{ }$ & & & $\sqrt{ }$ \\
\hline 17 & & $\sqrt{ }$ & & $\sqrt{ }$ & $\sqrt{ }$ & & & $\sqrt{ }$ & $\sqrt{ }$ & \\
\hline 18 & & $\sqrt{ }$ & & $\sqrt{ }$ & & $\sqrt{ }$ & & $\sqrt{ }$ & $\sqrt{ }$ & \\
\hline 19 & $\sqrt{ }$ & & & $\sqrt{ }$ & $\sqrt{ }$ & & $\sqrt{ }$ & & & $\sqrt{ }$ \\
\hline 20 & $\sqrt{ }$ & & & $\sqrt{ }$ & & $\sqrt{ }$ & $\sqrt{ }$ & & & $\sqrt{ }$ \\
\hline
\end{tabular}

Note: (-) No paved shoulder set in these shared lanes 


\subsection{Video recordings}

\section{Details of instrumentation}

Figure 2 gives examples of the setting of marked tapes and cameras in a shared lane. Reflective adhesive tapes were pasted across the road surface to form two white markers $15 \mathrm{~m}$ apart along the road to identify the survey section of the shared lane. As shown in the figure, each marker was cross-marked along the width of the road using short lengths of adhesive tape at $20 \mathrm{~cm}$ intervals to measure lateral separation between two modes.

In order to minimise blind spots in the recordings, three high-vision video cameras recorded the traffic flow during the survey period. Cameras were set up in an unobtrusive manner (e.g. in the median between the shared lane and pavement) to avoid influencing lane user behaviour while being monitored. The first camera (marked A in Figure 2) was set up facing east, and the second and third cameras (marked $\mathrm{B}_{1}$ and $\mathrm{B}_{2}$ ) were facing west. The height of camera $B_{1}$ was $1.5 \mathrm{~m}$ to approximate the eye height of e-motorcyclists or cyclists. Similarly,

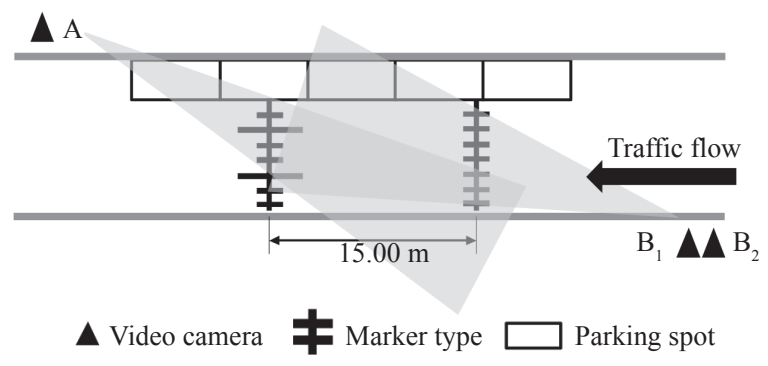

Figure 2 - Schematic layout diagram of the survey site of a shared lane

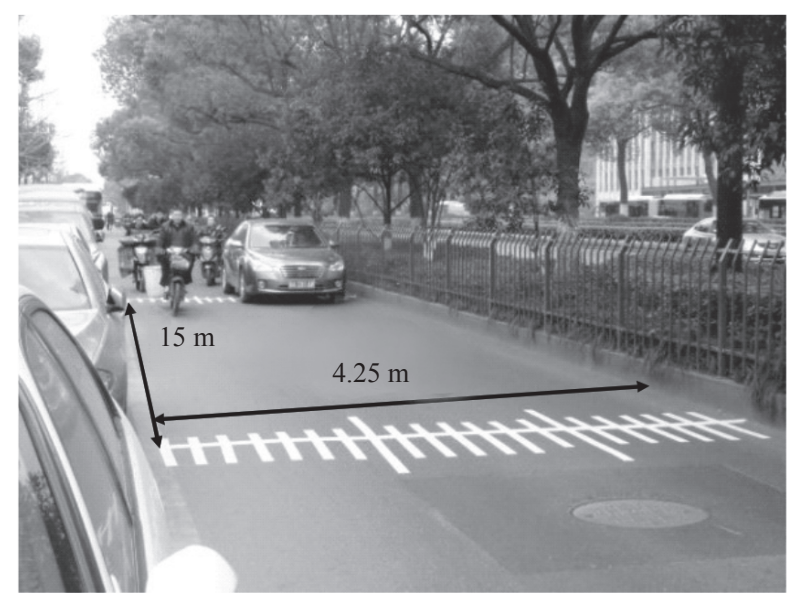

a) Original video image of the survey in progress the height of camera $\mathrm{B}_{2}$ was about $1.3 \mathrm{~m}$ to approximate the eye height of car drivers. Both camera $B_{1}$ and $\mathrm{B}_{2}$ were used in the questionnaire survey to estimate perception of satisfaction of three groups of lane users. Traffic flow in the shared lane is from east to west. The video recordings were stored on hard disks with a 20-hour recording capacity. The recordings were downloaded to a computer and trained students replayed the videos to take relevant measurements. The same method of marked tape setting and video recording was used in 20 selected shared lanes as well.

The survey was carried out over 10 fair weather weekdays in October 2018. The survey was conducted twice each day: each survey session was two hours long during off-peak traffic periods. The first session in the morning was from 9:00 a.m. to 11:00 a.m. and the second session in the afternoon was from 2:00 p.m. to 4:00 p.m.

\section{Video analysis}

Three types of measurements were obtained and analysed from the videos.

1) Traffic volume of shared lanes.

2) Speed of each vehicle along the straight stretch of lane was obtained by timing the length of time taken for the front wheel of the vehicle to travel the 15-meter distance between the taped markers.

3) Lateral separation between vehicles was obtained using the $20 \mathrm{~cm}$ cross markers (pasted on the road surface) as a guide. Photograph of marker sites are shown in Figure 3a. The captured video was enhanced (using Adobe software) to extend the cross makers to provide complete reference lines on the computer monitor as shown

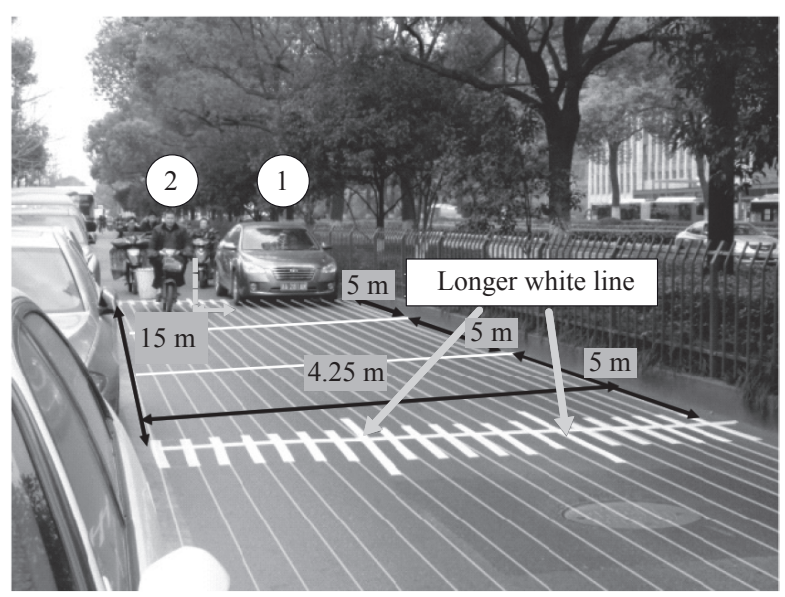

b) Image with reference lines enhanced

Figure 3 - Software enhancement of reference markers to increase accuracy of measurements 
in Figure $3 b$. For example, in Figure $3 b$, the lateral gap between car (marked as 1) and e-motorcycle (marked as 2) can be estimated as 4 strips (i.e., $80 \mathrm{~cm}$ ) with the aid of reference lines. The estimated gap distance is the distance between the left edge of the handlebar of the e-motorcyclist and the nearest edge of the front-right wheel of the car. Westerhuis et al. [24] previously described a similar technique.

\section{VR video conversion}

The video recordings from camera $B_{1}$ and $B_{2}$ were converted to VR video by software UtoVR and then stored in an iPhone with a resolution of $3840 \times 1920$ pixels. The iPhone was combined with virtual reality (VR) equipment to present video recordings for participants. The VR equipment included a pair of VR glasses with blue ray lens (see Figure 4) and headphones. Both video and sound provided an immersive environment for participants.

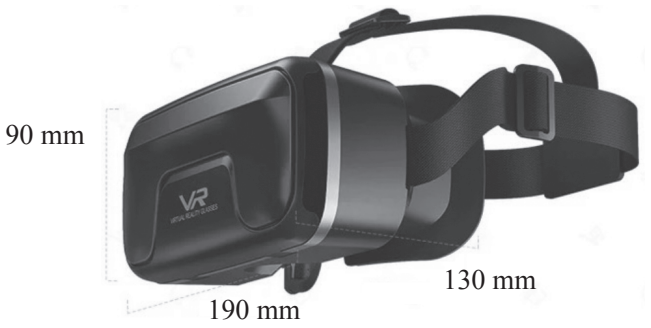

Figure 4-The virtual reality glasses used in the survey

\subsection{Questionnaire survey}

Participants were asked to watch video recordings of various shared lanes and to rate their level of satisfaction, supposing they were using these lanes with their main transport mode. Participants needed to rate their level of satisfaction for each lane in differing conditions. There were 40 video clips for this survey in total. Twenty clips were prepared for each lane and the remaining 20 clips repeated the same lane but with different traffic volumes. All clips were selected from the middle of the video recording instead of beginning or ending in order to avoid influence of setting up and removing instruments. Each clip contained three transport modes displayed to make participants have a direct feeling towards a shared lane environment. Each VR video clip for one condition was about thirty seconds in duration with a five second break between two consecutive recordings. During the 5 -second break period, participants were expected to complete the satisfaction survey by an intuitive reaction. For reliability check, all clips were displayed twice. The satisfaction level was a standard 5-point scale ranging from $1=$ 'Strongly dissatisfied' to $5=$ 'Strongly satisfied'.

\subsection{Model and analysis}

It is acknowledged that level of satisfaction should be measured by a set of variables [25, 26]. Therefore, independent variables, including traffic conditions and lane characteristics, were used in the model (see Figure 5).

The dependent variable: satisfaction level is shown as $Y_{j}(j=1,2,3,4,5)$. Finally, the model can be described as:

$Y_{j}=\beta_{0 j}+\beta_{1 j} x_{1}+\beta_{2 j} x_{2}+\ldots+\beta_{n j}+x_{n}$

where $x_{n}$ is a vector of independent variables, $\beta_{n j}$ is a regression coefficient, and $\beta_{0 j}$ is a constant parameter.

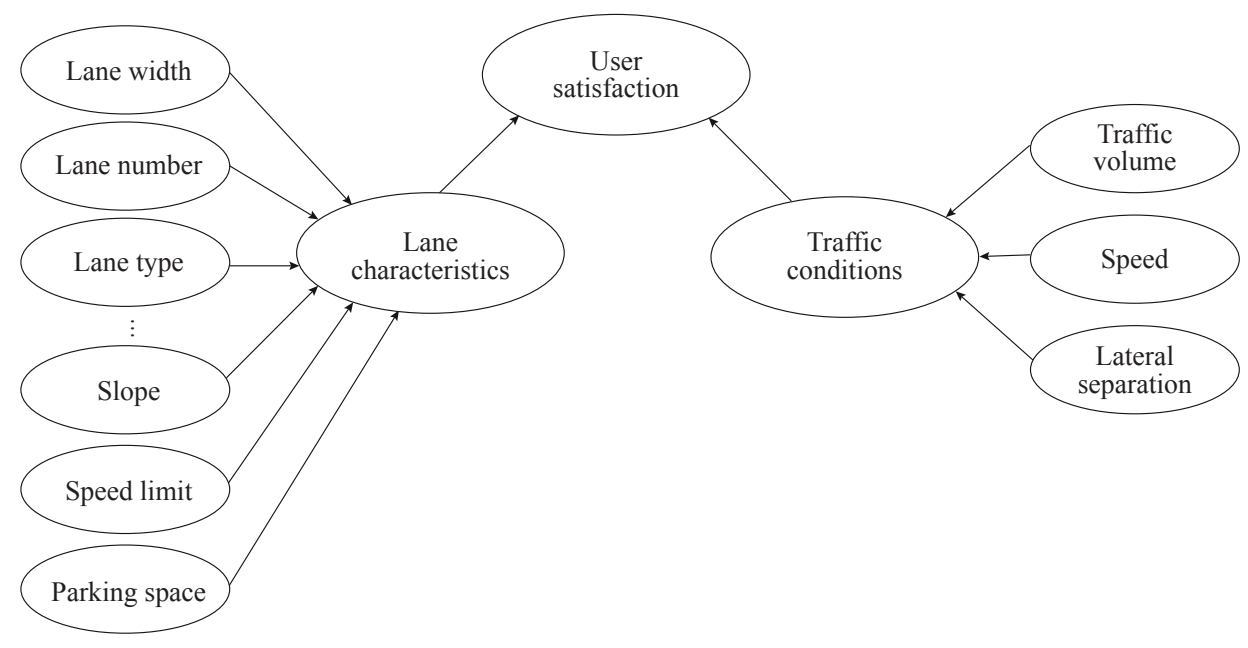

Figure 5-Structure of the user satisfaction model 
The satisfaction level of users was a discrete variable scaled from 1 to 5 as mentioned before, hence, the connection between the dependent variable and independent variables can be explained by a logistic regression model. In this study, we selected the multinomial ordered logistic regression model because the dependent variables are classified into five categories and there is an ordered relationship between them. The multinomial ordered logistic regression model has been proven as a suitable model to examine the correlation between satisfaction and various independent variables $[27,28]$. The structure of this model is as follows:

$$
\begin{aligned}
& \log i t\left(p_{1}\right)=\ln \left(\frac{p_{1}}{1-p_{1}}\right)=\beta_{01}+\beta_{11} x_{1}+\ldots+\beta_{n 1} x_{n} \\
& \log i t\left(p_{1}+p_{2}\right)=\ln \left(\frac{p_{1}+p_{2}}{1-\left(p_{1}+p_{2}\right)}\right)=\beta_{02}+\beta_{12} x_{1} \\
& +\ldots+\beta_{n 2} x_{n} \\
& \log i t\left(p_{1}+p_{2}+p_{3}\right)=\ln \left(\frac{p_{1}+p_{2}+p_{3}}{1-\left(p_{1}+p_{2}+p_{3}\right)}\right) \\
& =\beta_{03}+\beta_{13} x_{1}+\ldots+\beta_{n 3} x_{n} \\
& \log i t\left(p_{1}+p_{2}+p_{3}+p_{4}\right)=\ln \left(\frac{p_{1}+p_{2}+p_{3}+p_{4}}{1-\left(p_{1}+p_{2}+p_{3}+p_{4}\right)}\right) \\
& =\beta_{04}+\beta_{14} x_{1}+\ldots+\beta_{n 4} x_{n}
\end{aligned}
$$

Table 2 - Lane characteristics and traffic conditions where $p_{1}, p_{2}, p_{3}, p_{4}$ is the probability of satisfaction level.

Statistical analysis was performed by using IBM SPSS Statistics 24 for Windows ${ }^{\mathrm{TM}}$. It is noteworthy that we were checking for multicollinearity among independent variables and the parallel line assumption. The detailed estimation method of the logistic regression model is referenced in the research contents of Luce [29]. We will not present it in detail in this paper.

\section{RESULTS}

\subsection{Lane characteristics and traffic conditions}

Table 2 shows lane characteristics and traffic con-

\begin{tabular}{|c|c|c|}
\hline Item & Variable & Description \\
\hline \multirow{17}{*}{ 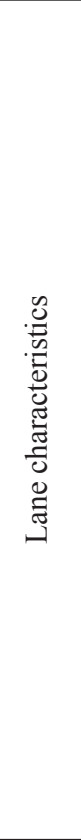 } & Lane width $[\mathrm{m}]$ & Minimum=5.5;Maximum=9.8; Mean=7.1; $\mathrm{Std}=0.9$ \\
\hline & Paved shoulder width $[\mathrm{m}]$ & Minimum $=0.3 ;$ Maximum $=1.5 ;$ Mean $=0.6 ; \mathrm{Std}=0.4$ \\
\hline & Speed limit $[\mathrm{km} / \mathrm{h}]$ & Minimum $=30.0 ;$ Maximum $=40.0 ;$ Mean $=36.0 ; \mathrm{Std}=5.0$ \\
\hline & \multirow{2}{*}{ Lane number } & 0 (single lane) \\
\hline & & 1 (two lanes or more) \\
\hline & \multirow{3}{*}{ Slope } & 0 (horizontal) \\
\hline & & 1 (upslope) \\
\hline & & 2 (downslope) \\
\hline & \multirow{3}{*}{ Lane type } & 0 (commuting lane) \\
\hline & & 1 (residential area) \\
\hline & & 2 (others) \\
\hline & \multirow{2}{*}{ Parking space } & 0 (no) \\
\hline & & 1 (yes) \\
\hline & \multirow{2}{*}{ Sidewalk } & 0 (no) \\
\hline & & 1 (yes) \\
\hline & \multirow{2}{*}{ Fence or greenbelt bordering the lane } & 0 (no) \\
\hline & & 1 (yes) \\
\hline \multirow{3}{*}{ 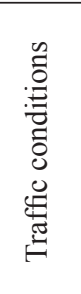 } & Traffic volume & $\begin{array}{l}\text { Car: } \text { mean=451.8; } \mathrm{Std}=117.1 ; \text { E-motorcycle: } \text { mean=726.4; } \mathrm{Std}=229.0 \\
\text { Bicycle: } \text { mean=644.8; } \mathrm{Std}=176.4\end{array}$ \\
\hline & Speed $[\mathrm{km} / \mathrm{h}]$ & $\begin{array}{l}\text { Car: } \text { mean }=36.5 ; \mathrm{Std}=8.6 ; \text { E-motorcycle: } \text { mean=35.4; } \mathrm{Std}=11.2 ; \text { Bicycle: } \\
\text { mean }=24.1 ; \mathrm{Std}=6.7\end{array}$ \\
\hline & $\begin{array}{l}\text { Frequency of lateral separation between } \\
\text { two transport modes less than } 40 \mathrm{~cm} \\
\text { (cases per hour) }\end{array}$ & Minimum=14; Maximum $=52 ;$ Mean $=25.4 ; \mathrm{Std}=8.3$ \\
\hline
\end{tabular}
ditions. These variables were used for the model in the following section.

\subsection{Model}

Before the analysis, the outliers that had values greater than two standard deviations from the mean (i.e., Outlier $=$ Mean score \pm 2.0 standard deviations) 
Lu W. Evaluating Satisfaction in Shared Lanes as Part of Sustainable Transport Infrastructure by Using VR Technology...

were excluded [30]. In the next step, we checked the multicollinearity by using multiple linear regression. Results showed no multicollinearity for three groups of users. The results of multinomial ordered logistic regression model for the three groups are presented in Table 3-5.

Tables 3, 4, and 5, respectively, show that some independent variables were identified in the groups of car drivers, e-motorcyclists, and cyclists. Lane width, lane number, lane type, and presence of parking space were identified in the car drivers group. Lane width, lane number, lane type, presence of parking space, speed, and lateral separation were the main factors for e-motorcyclists. For the group of cyclists, six independent variables (lane width,

Table 3 - Results of the car drivers group model

\begin{tabular}{||l|c|c||}
\hline \multirow{2}{*}{\multicolumn{1}{|c|}{ Variable }} & \multicolumn{2}{c||}{ Parameter estimates } \\
\cline { 2 - 3 } & Coefficient & Sig. \\
\hline \hline Lane width & $4.82^{* *}$ & 0.000 \\
\hline Lane number=1 & ref cat & \\
\hline Lane number=2 or more & $0.67 *$ & 0.042 \\
\hline Lane type=0 (commuting lane) & ref cat & \\
\hline Lane type=1 (residential area) & $1.84^{* *}$ & 0.000 \\
\hline Lane type=2 (others) & $1.16^{*}$ & 0.002 \\
\hline Parking space=0 (no) & ref cat & \\
\hline Parking space=1 (yes) & $0.57 * *$ & 0.000 \\
\hline Log-likelihood & -547.954 & \\
\hline R-Square & 0.742 & \\
\hline \hline
\end{tabular}

Note: *Sig. $<0.05, * *$ Sig. $<0.001$

Table 4 - Results of the e-motorcyclists group model

\begin{tabular}{||l|c|c||}
\hline \multirow{2}{*}{\multicolumn{1}{|c|}{ Variable }} & \multicolumn{2}{c|}{ Parameter estimates } \\
\cline { 2 - 3 } & Coefficient & Sig. \\
\hline \hline Lane width & $6.75^{* *}$ & 0.000 \\
\hline Lane number=1 & ref cat & \\
\hline Lane number=2 or more & $2.74^{*}$ & 0.035 \\
\hline Lane type=0 (commuting lane) & ref cat & \\
\hline Lane type=1 (residential area) & $4.03^{* *}$ & 0.000 \\
\hline Lane type=2 (others) & $3.81^{*}$ & 0.002 \\
\hline Parking space=0 (no) & ref cat & \\
\hline Parking space=1 (yes) & $-2.43^{* *}$ & 0.000 \\
\hline Speed & $-3.52^{* *}$ & 0.000 \\
\hline Lateral separation & $-4.21^{* *}$ & 0.000 \\
\hline & & \\
\hline Log-likelihood & -845.836 & \\
\hline R-Square & 0.671 & \\
\hline
\end{tabular}

Note: ${ }^{*}$ Sig. $<0.05, * *$ Sig. $<0.001$
Table 5 - Results of the cyclists group model

\begin{tabular}{||l|c|c||}
\hline \multirow{2}{*}{\multicolumn{1}{|c|}{ Variable }} & \multicolumn{2}{c|}{ Parameter estimates } \\
\cline { 2 - 3 } & Coefficient & Sig. \\
\hline \hline Lane width & $9.47^{* *}$ & 0.000 \\
\hline Lane number=1 & ref cat & \\
\hline Lane number=2 or more & $0.43^{*}$ & 0.027 \\
\hline Slope=0 (horizontal) & ref cat & \\
\hline Slope=1 (upslope) & $-2.95^{* *}$ & 0.000 \\
\hline Slope=2 (downslope) & $5.38^{* *}$ & 0.000 \\
\hline Parking space=0 (no) & ref cat & \\
\hline Parking space=1 (yes) & $-3.43^{*}$ & 0.001 \\
\hline Speed & $-4.27^{* *}$ & 0.000 \\
\hline Lateral separation & $-4.21^{* *}$ & 0.000 \\
\hline & & \\
\hline Log-likelihood & -731.476 & \\
\hline R-Square & 0.689 & \\
\hline
\end{tabular}

Note: *Sig. $<0.05, * *$ Sig. $<0.001$

lane number, presence of slope, presence of parking space, speed, and lateral separation) were also identified.

Based on the result of the test of parallel lines $(\mathrm{P}>0.05)$, all models satisfied the parallel line assumption. The likelihood chi-square test indicated that the models were statistically significant $(\mathrm{P}<0.001)$.

\section{DISCUSSION}

The purpose of this research is to identify the correlates of the levels of satisfaction of drivers, e-motorcyclists, and cyclists and influencing factors on the sustainable transport infrastructure (e.g. shared lane) on the questionnaire survey.

The findings indicate that lane width, lane number, and presence of parking space are the three potential common factors that may affect the levels of satisfaction in the three user groups. Based on the analysis, the lane width and number of lanes have a positive influence on satisfaction. The possible reason is that the wider lane or increasing number of lanes leads to a relative ease of driving or riding [31]. The factor of presence of parking space tends to be a positive influence in satisfaction of car drivers; however, it is shown as a negative effect on perception of satisfaction of e-motorcyclist and 
cyclists. This finding may be attributable to the fact that drivers directly obtained more spaces to park but e-motorcyclist and cyclists have to face narrower travel space and face risk of collision with car door opening when they pass the parked cars.

Lane type is considered as one of many potential factors which correlated with satisfaction for motorists and e-motorcyclists. These shared lanes in residential areas have a positive influence. Results from the motorists and e-motorcyclists model have implied that most participants preferred shared lanes in residential areas rather than using commuting lanes. In our questionnaire survey, many motorists and e-motorcyclists actually expressed that they did not feel anxious or upset when they entered residential areas, which also matches the results of the model. Some possible reasons may be relatively less traffic and more green space compared to those shared lanes in the commuting areas. In our survey, we have measured that the traffic volume in residential areas was much lower than in commuting areas. For example, there were about 360 cars, 540 e-motorcycles, and 510 bicycles per hour on average in shared lanes in residential areas. On the other hand, around 490 cars, 820 e-motorcycles, and 750 bicycles per hour on average in commuting areas. However, we did not find strong evidence that the factor of lane type was linked to satisfaction for cyclists, although some previous studies have indicated that there is a significant relationship between cyclists and lane types. For example, Hatfield et al. [11] showed that cyclists were not satisfied with shared lanes in commuting areas. Nevertheless, in our questionnaire, some cyclists have reported that they worried about their safety with the increasing speed by cars and e-motorcycles in shared lanes of residential areas. In fact, we have found that speeding occurred for several cars and e-motorcycles in residential areas which did not happen in commuting areas. However, it is worth noting that speeding may not occur in a lower traffic volume environment in western countries due to differing driving behaviours from China [32].

The findings indicated that lateral separation was an important factor which might cause changes of satisfaction levels for the group of cyclists. In fact, many previous studies have indicated that lane width [33] and traffic volume [34] significantly affect the lateral position of vehicles and bicycles in mixed lanes. In our study, we also found that lateral separation between two transport modes was closer in a narrower lane or when traffic volume increased which is consistent with previous studies. However, based on video recording, we also found in some cases with lower traffic volume that the lateral separation was still less than $40 \mathrm{~cm}$ when e-motorcycles overtook bicycles. This was not reported by other literature. We guessed this surprising phenomenon was due to the fact that the widths of e-motorcycles were small and some e-motorcyclists overestimated the real lateral separation with bicyclists. In addition, many participants who were cyclists confirmed they need a wider space to avoid crashes with vehicles. For example, Kiyota et al. [35] have used heartbeat measurement instruments to show that reduction of lateral separation caused measurable physiological stress for cyclists who were being overtaken by cars in a shared lane. Such stressful situations may cause difficulties for inexperienced or older cyclists causing them to ride bicycles (or e-motorcycles) with a wobbly behaviour that could impart anxiety to nearby road users. In addition, small lateral separation is likely to cause collision or near-miss events which decreases satisfaction level. Fu [36] and $\mathrm{He}$ et al. [37] mentioned that close lateral separation between two modes would lead to an increasing likelihood of accidents.

Presence of upslope was negatively related to the satisfaction of cyclist due to the difficulty of riding. The finding is consistent with the previous study of Harkey et al. [19]. However, presence of slope was not found a significant connection in groups of motorist and e-motorcyclist. It is not surprising because cars and e-motorcycles provide motive power for driving and riding. The factor of speed demonstrated a significant connection with the levels of satisfaction in the groups of e-motorcyclist and cyclist. In fact, there are continuous controversies about speed limits of shared lanes in China. For example, Liu [38] argued that the speed limit for e-motorcycles in the shared lane should increase to $30-35 \mathrm{~km} / \mathrm{h}$ due to e-motorcycles being used as small and fast delivery transport vehicles for express services, such as EMS, China Post, and food delivery services. Nevertheless, the main worries were close lateral spacing between traffic modes and a relatively high speed, which is consistent with the previous studies [39]. Cars and e-motorcycles are two modes of transport which should be able to travel at a stable speed, and should not always have to slow down and weave around slower bicycles. Bicycles should not have to share the lane with 
other modes, which pass them at high speeds and cause riders to feel worried about their safety. An ideal shared lane solution should ensure that all users of the lane feel safe and comfortable.

Shared lanes in China have proven to be an efficient use of space by removing the previous lane constraints on cars, while allowing parking within some lane space, and mixing transport modes with different characteristics. For the foreseeable future, shared lanes will continue to be widely used in urban China due to the limits of road resources in major cities. It is evident that the development of methods available to improve shared lanes and increase level of satisfaction of users without sacrificing the simplicity of the shared lane concept needs creative input from government agencies and professionals such as researchers, engineers, and planners. Our study provides reference for local government officials and planners. They could consider using results of our study to do analysis and make a decision for a better travel environment. For example, lane width could be expanded if the conditions allow it. The angle of slope for cyclists should be considered more cautiously. The appropriate speed limit for different transport modes should be considered. In addition, the methodology in our study is not complicated and can save lots of time and money because we can display different traffic conditions in the video for each participant instead of requiring participants to report from the field. Our findings also offer methodology, variables, and analysed data to other countries that are considering improving other types of transport infrastructures.

There are also some limitations in the present study. One of the limitations of this study is that we did not consider more variables, such as quality of pavement of shared lanes which may affect lane users' satisfaction [40]. The reason we did not add this variable is because the pavement condition of the twenty shared lanes in the study was good. We may add more variables in the model when we analyse shared lanes in other cities or other road segments.

The other limitation of this study is that the speeds of modes were measured by timing the length of time taken for the front wheel of the vehicle to travel the 15-meter distance between the white-taped markers. These white-taped markers may divert attentions of users and consequently cause them to change speeds of modes. Taped markers may slightly change tracks of lane users as well.
In addition, we could not ascertain whether the self-reported data by the participants in the survey was true or not [41, 42]. The participants may select an option that is more amenable to their support for a certain transport mode. This may be more prominent in the car drivers group because they were more likely to use parking spaces available in the shared lane. In addition, it is noteworthy that there may be subtle differences of perception of satisfaction between the real world and in watching VR video recording. For example, participants might grade their experience higher due to the "wow factor", particularly during their first use of VR [43]. In addition, the samples of participants which have a high level of discomfort due to sensitivity to a 360 degree perspective during the VR survey should be deleted.

\section{CONCLUSION}

This paper has set out to investigate user perceptions about shared lanes. The association between satisfaction of users, traffic condition and lane characteristics has been examined by a multinomial ordered logistic regression model. Our conclusions are summarised as follows: Satisfaction of car drivers was mainly affected by lane width, lane number, lane type, and presence of parking space. Lane width, lane number, lane type, presence of parking space, speed, and lateral separation were the main factors in the e-motorcyclist group. For the group of cyclists, lane width, lane number, presence of slope, presence of parking space, speed, and lateral separation were identified as the main factors. In addition, we did not find any significance of the lane type when it comes to the satisfaction of bicyclists. Our study has shown that VR technology is helpful and useful in user satisfaction research regarding shared lanes. Local officials and planners can also consider applying this new methodology, variables, and analysed data in other areas.

In the future, we need to recruit participants who have some experience using VR and apply a simulator sickness questionnaire to confirm whether or not there was simulation sickness in order to delete those samples in which participants experienced high levels of discomfort. Through a field survey of shared lane users we can check users' satisfaction and testify to the accuracy of the results of VR survey. Moreover, some new influential factors may be found from a field survey in the real world as well. 


\section{ACKNOWLEDGEMENTS}

The author would like to thank Professors Xunyou Ni, Chunqin Zhang, Xiaoyuan Zhang, and Master's degree student Tingting Chen for their revisions. The research described in this paper is supported by the National Natural Science Foundation of China (Grant No. 71901196), the First-Class Disciplines Project of Civil Engineering in Zhejiang Province, and Philosophy and Social Science Project of Zhejiang Province, China (Grant No. 19NDQN361YB).

陆维特, 博士, 副教授

浙江理工大学建筑工程学院

中国杭州310018

使用虚拟现实技术评估作为可持续交通基础设 施一部分的共享车道满意度: 来自中国城市的 证据

\section{摘要:}

由于城市资源有限, 交通基础设施共享的概念在 可持续社会中日益突出。为了克服道路空间不足, 满足日益增长的交通需求, 中国城市已经推广了允 许机动车、电动摩托车和自行车进入的共享车道。 基于虚拟现实视频和问卷调查, 本研究发现机动车 驾驶员、电动摩托车使用者和自行车使用者的满意 度水平与共享车道的交通状况和车道特性相关。运 用有序多分类逻辑回归模型对数据进行分析发现:

(1) 驾驶员满意度主要由车道宽度、车道数、车道 类型和是否有停车位因素影响; (2) 车道宽度、车 道数、车道类型、是否有停车位、车速和横向间距 是影响电动摩托车使用者满意度的主要因素; (3) 车道宽度、车道数、是否有坡度、是否有停车位、 车速和横向间距是影响自行车使用者满意度的主要 因素。本研究将有助于当地政府有关部门设计更有 效的可持续交通基础设施。

\section{关键词:}

可持续交通基础设施; 用户满意度; 交通状况; 车道特性; 有序多分类逻辑回归模型

\section{REFERENCES}

[1] Davydova T, Zhutaeva E, Dubrovskaya T. Prediction of the demographic situation in urban districts as a factor of sustainable social and economic development of the transport infrastructure. IOP Conference Series Earth and Environmental Science. 2017;90: 012168. DOI: 10.1088/1755-1315/90/1/012168

[2] Hardinghaus M, Papantoniou P. Evaluating cyclists' route preferences with respect to infrastructure. Sustainability. 2020;12(8): 3375. DOI: 10.3390/su12083375

[3] Ma J, Zhao Y. Study on the adaptability of the level of urban transportation infrastructure and economic development. Applied Mechanics and Materials.
2013;361-363: 1950-1953. DOI: 10.4028/www.scientific.net/AMM.361-363.1950

[4] Sun Y, Cui Y. Evaluating the coordinated development of economic, social and environmental benefits of urban public transportation infrastructure: Case study of four Chinese autonomous municipalities. Transport Policy, 2018;66: 116-126. DOI: 10.1016/j.tranpol.2018.02.006

[5] Aljoufie $\mathrm{M}$, et al. Urban growth and transport infrastructure interaction in Jeddah between 1980 and 2007. International Journal of Applied Earth Observation \& Geoinformation. 2013;21: 493-505. DOI: 10.1016/j. jag.2012.07.006

[6] Tilahun NY, Levinson DM, Krizek KJ. Trails, lanes, or traffic: Valuing bicycle facilities with an adaptive stated preference survey. Transportation Research Part A: Policy and Practice. 2007;41: 287-301. DOI: 10.1016/ j.tra.2006.09.007

[7] Garrard J, Rose G, Lo SK. Promoting transportation cycling for women: The role of bicycle infrastructure. Preventive Medicine, 2008;46: 55-59. DOI: 10.1016/ j.ypmed.2007.07.010

[8] Nan TW, Mao BH, Chen ZJ, Xu Q. Urban mixed non-motor vehicle flow character simulation based on cellular automata. Journal of Highway and Transportation Research and Development. 2014;31(1): 104-109. Chinese.

[9] Cherry C, Cervero R. Use characteristics and mode choice behavior of electric bike users in China. Transport Policy. 2007;14(3): 247-257. DOI: 10.1016/j.tranpol.2007.02.005

[10] Chong S, et al. Relative injury severity among vulnerable non-motorised road users: Comparative analysis of injury arising from bicycle-motor vehicle and bicycle-pedestrian collision. Accident Analysis and Prevention. 2010;42: 290-296. DOI: 10.1016/j.aap.2009.08.006

[11] Hatfield J, Prabhakharan P. An investigation of behaviour and attitudes relevant to the user safety of pedestrian/ cyclist shares paths. Transportation Research Part F: Traffic Psychology \& Behaviour. 2016;40: 35-42. DOI: 10.1016/j.trf.2016.04.005

[12] Wood JM, Lacherez PF, Marszalek RP, King MJ. Drivers' and cyclists' experience of sharing the road: Incidents, attitude and perception of visibility. Accident Analysis and Prevention. 2009;41: 772-776. DOI: 10.1016/ j.aap.2009.03.014

[13] Hatfield J, et al. Factors associated with cyclists' self-reported choice of lane position. Transportation Research Part F: Traffic Psychology \& Behaviour. 2018;55: 403414. DOI: 10.1016/j.trf.2018.03.016

[14] National Bureau of Statistics of the People's Republic of China. Analysis of accidents of cycles and scooters in China in 2017. Available from: http://data.stats.gov.cn/ [Accessed 15th Oct. 2019].

[15] Li L, Yang JK, Otte D. Study on vehicle-electric bicycle impact accidents in Changsha District. The $9^{\text {th }}$ INFATS Proceedings of the International Forum of Automotive Traffic Safety, Changsha, China. 2011; p. 219-222.

[16] Landis B, Vattikuti V, Brannick M. Real-time human perceptions: Toward a bicycle level of service. Transportation Research Record. 1997;1578: 119-126. DOI: $10.3141 / 1578-15$

[17] Bai L, Chan CY, Liu P, Xu C. Identifying factors 
affecting the safety of mid-block bicycle lanes considering mixed two-wheeled traffic flow. Traffic Injury Prevention. 2017;18(7): 761-766. DOI: 10.1080/15389588.2017.1303681

[18] Jensen S. Pedestrian and bicyclist level of service on roadway segments. Transportation Research Record. 2007;2031: 43-51. DOI: 10.3141/2031-06

[19] Harkey D, Reinfurt D, Knuiman M, Stewart JR. The bicycle compatibility index: A level of service concept. Report No. FHWA-RD-98-095, FHWA, McLean, 1998.

[20] Lehtonen E, et al. Evaluating bicyclists' risk perception using video clips: Comparison of frequent and infrequent city cyclists. Transportation Research Part F: Traffic Psychology \& Behaviour. 2016;41: 195-203. DOI: 10.1016/j.trf.2015.04.006

[21] Lamb JS, et al. Should we pass on minimum passing distance laws for cyclists? Comparing a tactical enforcement option and minimum passing distance laws using signal detection theory. Transportation Research Part F: Traffic Psychology and Behaviour. 2020;70: 275-289. DOI: 10.1016/j.trf.2020.03.011

[22] Liu Q, Homma R, Iki K. Evaluating cyclists' perception of satisfaction using $360^{\circ}$ videos. Transportation Research Part A: Policy and Practice. 2020;132: 205-213. DOI: $10.1016 /$ j.tra.2019.11.008

[23] Hangzhou Bureau of Statistics. Hangzhou statistical yellow book. Hangzhou, Zhejiang, China: Hangzhou Bureau of Statistics; 2019. p. 25-41.

[24] Westerhuis F, Jelijs LH, Fuermaier ABM, Waard DD. Using optical illusions in the shoulder of a cycle path to affect lateral position. Transportation Research Part F: Psychology \& Behaviour. 2017;48: 38-51. DOI: 10.1016/j.trf.2017.04.014

[25] Zhang C, Liu Y, Lu W, Xiao G. Evaluating passenger satisfaction index based on PLS-SEM model: Evidence from Chinese public transport service. Transportation Research Part A: Policy and Practice. 2019;120: 149164. DOI: $10.1016 /$ j.tra.2018.12.013

[26] Zhang C, Juan Z, Lu W, Xiao G. Do the organizational forms affect passenger satisfaction? Evidence from Chinese public transport service. Transportation Research Part A: Policy and Practice. 2016;94: 129-148. DOI: 10.1016/j.tra.2016.09.007

[27] Mccormick JL, Porter TK. Effect of fishing success on angler satisfaction on a central Oregon rainbow trout fishery: Implications for establishing management objectives. North American Journal of Fisheries Management. 2014;34(5): 938-944. DOI: 10.1080/02755947.2014.932869

[28] Prabhu KL, et al. Is quality important to our patients? the relationship between surgical outcomes and patient satisfaction. BMJ Quality \& Safety. 2018;27(1): 48-52. DOI: 10.1136/bmjqs-2017-007071

[29] Luce RD. On the possible psychophysical laws. Psychological Review. 1959;66(2): 80-81. DOI: 10.1037/ h0043178
[30] Miller J. Reaction time analysis with outlier exclusion: Bias varies with sample size. Quarterly Journal of Experimental Psychology a Human Experimental Psychology. 1991;43(4): 907-912. DOI: 10.1111/j.1469-8986.1991. tb01017.x

[31] Kang K, Lee K. Development of a bicycle level of service model from the user's perspective. KSCE Journal of Civil Engineering. 2012;16(6): 1032-1039. DOI: 10.1007/s12205-012-1146-Z

[32] Huang YH, Roetting M, Wei Z. Factors determining driving behavior in China and the USA. $2^{\text {nd }}$ China International Forum on Work Safety; 2004. p. 374-379.

[33] Ibrahim MKA, et al. Evaluating the effect of lane width and roadside configurations on speed, lateral position and likelihood of comfortable overtaking in exclusive motorcycle lane. Accident Analysis \& Prevention. 2018;111: 63-70. DOI: 10.1016/j.aap.2017.10.023

[34] Wong KI, Lee TC, Chen YY. Traffic characteristics of mixed traffic flows in urban Arterials. Asian Transport Studies. 2016;4(2): 379-391. DOI: 10.11175/eastsats. 4.379

[35] Kiyota M, Sumi T, Oheda Y, Tanaka T. Cyclist's behavior model of keeping away from the passing automobile in a local street. Proceeding of Japan Society of Civil Engineers. 1995;524: 131-134. Japanese. DOI: 10.2208/ jscej.1995.524_131

[36] Fu Q. Study on traffic safety and management of electric motorbikes in urban. Ph.D. Thesis. Southwest JiaoTong University, China; 2016. p. 35-47. Chinese.

[37] He ZC, et al. Modelling car-following behaviour with lateral separation and overtaking expectation. Transportmetrica B: Transport Dynamics. 2015;4(3): 223-239. DOI: $10.1080 / 21680566.2015 .1083911$

[38] Liu SB. Reflections on the development of urban electric bicycles. Traffic \& Transportation. 2012;1: 129-132. Chinese.

[39] Lü XH, Lei GJ. Causes and safety of scooter traffic accidents in Nanning. Journal of Guangxi Police Academy. 2010;5: 5-7. Chinese.

[40] Bitelli G, Simone A, Girardi F, Lantieri C. Laser scanning on road pavements: A new approach for characterizing surface texture. Sensors. 2012;12(7): 9110-9128. DOI: $10.3390 / \mathrm{s} 120709110$

[41] Lu W, Zhang C, Ni X. Research on the rationale of width of disabled parking spaces and correlation of selection by wheelchair users and others. Journal of Transport and Health. 2019;12: 130-141. DOI: 10.1016/j. jth.2019.01.006

[42] Lu W, Zhang C, Ni X, Liu H. Do the elderly need wider parking spaces? Evidence from experimental and questionnaire surveys. Sustainability. 2020:12(9): 3800. DOI: 10.3390/su12093800

[43] Mrvelj Š, Matulin M, Martirosov S. Subjective evaluation of user quality of experience for omnidirectional video streaming. Promet - Traffic\&Transportation. 2020;32(3): 409-421. DOI: 10.7307/ptt.v32i3.3444 